\title{
Interactions between dietary patterns and genetic factors in relation to incident dementia among 70-year-olds
}

\author{
Jessica Samuelsson ${ }^{1}$ (i) $\cdot$ Jenna Najar ${ }^{1,2} \cdot$ Ola Wallengren $^{3} \cdot$ Silke Kern $^{1,2} \cdot$ Hanna Wetterberg $^{1}$. \\ Madeleine Mellqvist Fässberg ${ }^{1}$. Henrik Zetterberg ${ }^{4,5,6,7} \cdot$ Kaj Blennow $^{4,5} \cdot$ Lauren Lissner $^{8}$. Elisabet Rothenberg ${ }^{9}$. \\ Ingmar Skoog ${ }^{1,2} \cdot$ Anna Zettergren ${ }^{1}$
}

Received: 7 July 2021 / Accepted: 28 September 2021 / Published online: 10 October 2021

(c) The Author(s) 2021

\begin{abstract}
Purpose To investigate potential interactions between dietary patterns and genetic factors modulating risk for Alzheimer's disease (AD) in relation to incident dementia.

Methods Data were derived from the population-based Gothenburg H70 Birth Cohort Studies in Sweden, including 602 dementia-free 70-year-olds (examined 1992-93, or 2000-02; 64\% women) followed for incident dementia until 2016. Two factors from a reduced rank regression analysis were translated into dietary patterns, one healthy (e.g., vegetables, fruit, and fish) and one western (e.g., red meat, refined cereals, and full-fat dairy products). Genetic risk was determined by APOE $\varepsilon 4$ status and non- $A P O E \mathrm{AD}$-polygenic risk scores (AD-PRSs). Gene-diet interactions in relation to incident dementia were analysed with Cox regression models. The interaction $p$ value threshold was $<0.1$.

Results There were interactions between the dietary patterns and APOE $\varepsilon 4$ status in relation to incident dementia (interaction $p$ value threshold of $<0.1$, while no evidence of interactions were found between the dietary patterns and the AD-PRSs. Those with higher adherence to a healthy dietary pattern had a reduced risk of dementia among $\varepsilon 4$ non-carriers (HR: 0.77; 95\% CI: $0.61 ; 0.98$ ), but not among $\varepsilon 4$ carriers (HR: 0.86; CI: $0.63 ; 1.18$ ). Those with a higher adherence to the western dietary pattern had an increased risk of dementia among $\varepsilon 4$ carriers (HR: 1.37; 95\% CI: 1.05; 1.78), while no association was observed among $\varepsilon 4$ non-carriers (HR: 0.99; CI: 0.81; 1.21).

Conclusions The results of this study suggest that there is an interplay between dietary patterns and APOE $\varepsilon 4$ status in relation to incident dementia.
\end{abstract}

Keywords Dietary pattern $\cdot$ Nutrition $\cdot$ Dementia $\cdot$ Apolipoprotein E genotype $\cdot$ Polygenic risk score

Ingmar Skoog and Anna Zettergren are joint senior authors.

Jessica Samuelsson

jessica.samuelsson@neuro.gu.se

1 Neuropsychiatric Epidemiology Unit, Department of Psychiatry and Neurochemistry, Institute of Neuroscience and Physiology, Sahlgrenska Academy, Centre for Ageing and Health (AGECAP) at the University of Gothenburg, Wallinsgatan 6, 43141 Mölndal, Sweden

2 Region Västra Götaland, Sahlgrenska University Hospital, Psychiatry, Cognition and Old Age Psychiatry Clinic, Gothenburg, Sweden

3 Clinical Nutrition Unit, Sahlgrenska University Hospital, Gothenburg, Sweden

4 Clinical Neurochemistry Laboratory, Sahlgrenska University Hospital, Mölndal, Sweden
5 Department of Psychiatry and Neurochemistry, Institute of Neuroscience and Physiology, Sahlgrenska Academy at the University of Gothenburg, Gothenburg, Sweden

6 UK Dementia Research Institute at UCL, London, UK

7 Department of Neurodegenerative Disease, UCL Institute of Neurology, London, UK

8 School of Public Health and Community Medicine, Institute of Medicine, Sahlgrenska Academy, University of Gothenburg, Gothenburg, Sweden

9 Faculty of Health Sciences, Kristianstad University, Kristianstad, Sweden 


$\begin{array}{ll}\text { Abbreviations } \\ \text { APOE } & \text { Apolipoprotein E } \\ \text { AD } & \text { Alzheimer's disease } \\ \text { PRS } & \text { Polygenic risk score } \\ \text { MeDi } & \text { Mediterranean diet } \\ \text { MIND } & \begin{array}{l}\text { Mediterranean-DASH Intervention for neurode- } \\ \text { generative delay }\end{array} \\ \text { GWAS } & \text { Genome-wide association studies } \\ \text { SNP } & \text { Single-nucleotide polymorphism } \\ \text { RRR } & \text { Reduced rank regression } \\ \text { PC } & \text { Principal component }\end{array}$

\section{Introduction}

Genetic and lifestyle factors influence the risk of developing dementia $[1,2]$. Diet is one of the modifiable lifestyle factors thought to affect risk [3, 4], but whether there is an interplay with genetic risk factors is unclear $[5,6]$. Several nutrients and foods have been linked with the risk of developing dementia [7]. However, since foods are eaten in combination and contain multiple nutrients that might influence risk, there has been a shift from investigating single nutrients and foods towards investigating the impact of dietary patterns [8]. Healthier Mediterranean-style dietary patterns (MeDi), rich in foods such as wholegrain products, vegetables, pulses, fruits and berries, nuts and seeds, fish and seafood have been associated with reduced risk of dementia $[9,10]$, while western style dietary patterns with a higher content of foods such as red and processed meat, full-fat dairy products, refined cereal products, sweets and highsugar drinks have been associated with increased risk [7, 8, $11,12]$. However, people often eat a combination of healthy and unhealthy diets, and the cumulative effects of various nutrients and foods may affect risk differently depending on the combinations [13]. Studying the effect of different dietary patterns could, therefore, be useful to increase the understanding of food and nutrient combinations that may prevent or delay the onset of dementia.

The apolipoprotein $\mathrm{E}(A P O E)$ gene is the strongest genetic factor modulating risk for $\mathrm{AD}$ and dementia [14]. This gene has three common alleles, the protective allele $A P O E \varepsilon 2$, the neutral allele $A P O E \varepsilon 3$, and the risk allele $A P O E \varepsilon 4$ [14]. Through large genome-wide association studies (GWASs), additional AD-risk-modifying genetic variants have been identified [15]. These genetic variants have lower effect sizes and are often combined into polygenic risk scores (PRSs) [16]. Population-based studies have shown that PRSs for AD are associated with AD and allcause dementia [14, 17, 18], with disease progression [19], and with AD-pathology [17, 20-22].

It has been suggested that risk reducing effects from foods may differ depending on an individual's genetic risk profile
[23-25]. However, previous studies investigating interactions between dietary patterns and genetic risk factors in relation to cognitive function and dementia are limited (especially when it comes to non-APOE PRSs) and results are inconclusive, showing either no gene-diet interactions or risk reducing effects among either carriers or non-carriers of genetic risk factors [23, 25-27]. Results from studies investigating interactions between genetic risk factors (usually $A P O E$ ) and single foods or nutrients showed similar contradictive results [28-31].

The aim of this study was to investigate potential interactions between dietary patterns and genetic factors modulating risk for $\mathrm{AD}$ (i.e., $A P O E \varepsilon 4$ status and non- $A P O E \mathrm{AD}-$ PRSs) in relation to incident dementia among 70-year-olds.

\section{Materials and methods}

Data were derived from the ongoing population-based Gothenburg H70 birth cohort studies that started in 1971 [32], including the Population Study of Women in Gothenburg that started in 1968 [33]. Adults aged 70 years and living in Gothenburg at the time of selection were systematically selected based on birth dates. The Gothenburg H70 birth cohort studies include a wide range of examinations such as genetic, somatic, cognitive, psychiatric, and dietary examinations [34]. This study includes participants born 1922 and 1930, who were examined 1992-93 (born 1922) or 2000-02 (born 1930) and re-examined in 2000, 2005, 2009 and 2015-16. Dementia diagnosis for participants that were lost to follow-up between 2009 and 2015-16 were based on information from the Swedish inpatient registry until 2012 (there were no registry data on dementia diagnosis between 2012 and 2016 available). Information on deaths during follow-up was obtained from the Swedish population registry until 2016. There were 500 (66\% response rate) systematically selected 70-year-olds that participated in the 1992-93 examination, and the dietary examination was performed on a subsample of these participants $(n=199)$. There were 604 (71\% response rate) systematically selected 70-year-olds that participated in the 2000-02 examination, and all of them were invited to take part of the dietary examination $(n=554$ participated). Out of the 1104 participants with baseline examinations in either 1992-93 (born 1922) or 2000-02 (born 1930), there were a total of 753 (296 men and 457 women) with dietary data. Blood sampling for genetic analyses was performed in 2000-02. Out of the 753 participants with dietary data, there were 616 (393 women and 223 men) participants with genotype data and 615 (392 women and 223 men) with dementia data. The final sample comprised 602 (218 men and 384 women) participants who were free from dementia at baseline examinations, see sample flowchart in Fig. 1. 


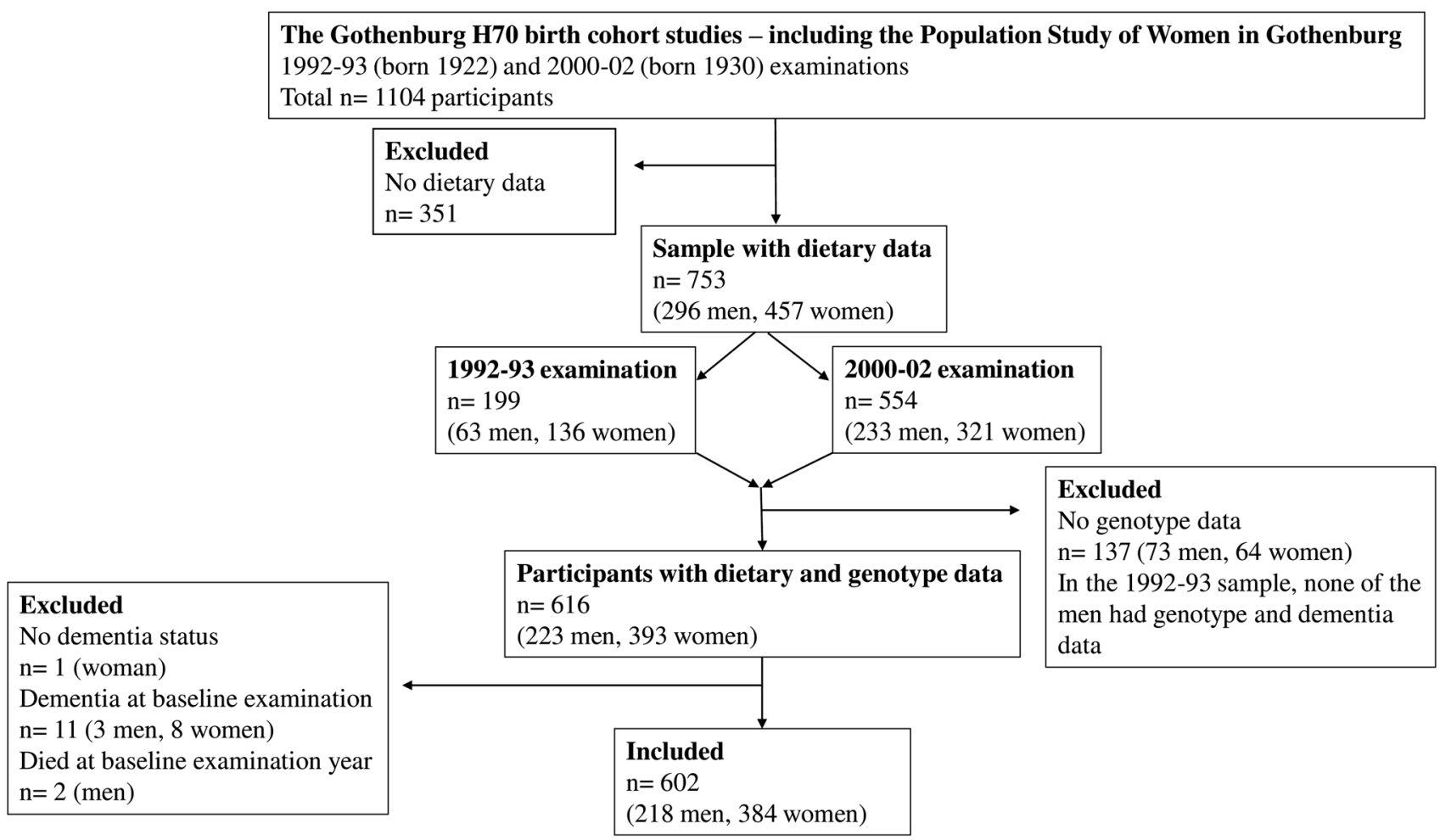

Fig. 1 Sample flowchart

\section{Dietary examination procedure}

Information on dietary intake was obtained at baseline examinations (1992-93 for those born 1922, and 2000-02 for those born 1930) with the diet history method (DH) [35, 36]. The DH used in this study was a semi-structured faceto-face interview, estimating food intake during the preceding 3 months. Trained registered dietitians performed the interviews at the participants own home or at the clinic. The protocols for the interviews consist of a meal-pattern interview, accompanied by a food list with questions on usual frequencies and portion sizes of foods. Pictures of foods from the Swedish National Food Agency (NFA) were used during the interviews to estimate individual portion sizes. Dietary intake was registered in grams of food items usually consumed per day/week/month in the NFA's nutrient database (PC-kost) in 2000-02. The DH method has been validated and described in detail previously [35-37].

\section{Dietary variables and construction of dietary patterns}

Mean daily energy, nutrient and food intake were calculated based on results from the DH interview. Reported food intake was placed into 30 food groups based on similarity of nutritional properties and biological classifications [38] (Supplementary Table 1) and transformed with Box-Cox transformation to normalize the distribution. The Box-Cox transformation is a family of power transform functions that are used to stabilize variance and make a dataset approach normal distribution. Dietary patterns were derived with reduced rank regression analysis (RRR) on the total dietary sample $(n=753)$. The RRR analysis was performed in SAS version 9.4 to reduce the data into factors representing dietary patterns with the 30 food groups as predictor variables [39]. The SAS code used for the RRR analysis has been described in detail previously [39]. The response variables in the RRR analysis were estimated vitamin E, C, folate, fibre, polyunsaturated fatty acids, saturated fatty acids, and alcohol intake (from the DH interview). These nutrients were selected as response variables based on potential associations with dementia risk. Vitamin E, C, folate, fibre, and polyunsaturated fatty acids have been associated with reduced risk of dementia, whereas saturated fatty acids and higher alcohol intake with increased risk [3, 40-46]. The aim of RRR is to explain as much variation of the response variables as possible, by simultaneously reducing the dimensionality of the predictor variables $[47,48]$. We chose the RRR approach since it allows us to explore dietary patterns in this population while still considering a priori knowledge about nutrients that have been associated with incident dementia. Data on nutritional supplements were not available.

Two out of five factors from the RRR analysis could be translated into dietary patterns based on factor loading 
thresholds $\leq-0.20$ and $\geq 0.20$ (Table 1 ). The factor loading thresholds were chosen based on previous studies where dietary patterns have been derived with RRR [49-51].

Table 1 Food item factor loadings for the "healthy" and the "western" dietary patterns derived by reduced rank regression analysis

\begin{tabular}{|c|c|c|}
\hline Dietary patterns & Healthy (factor 1) & Western (factor 2) \\
\hline Variation in responses (\%) & 33.3 & 14.9 \\
\hline Variation in predictors $(\%)$ & 6.5 & 6.2 \\
\hline Fish and seafood & $0.29 *$ & 0.11 \\
\hline Meat and processed meat & $0.29 *$ & $0.35 *$ \\
\hline Poultry & 0.17 & -0.03 \\
\hline Eggs & $0.31 *$ & 0.18 \\
\hline Potatoes & $0.30 *$ & $0.20 *$ \\
\hline $\begin{array}{l}\text { Vegetables, pulses, nuts and } \\
\text { seeds }\end{array}$ & $0.53 *$ & $-0.50^{*}$ \\
\hline Fruits and berries & $0.42 *$ & $-0.57 *$ \\
\hline Keyhole $^{\mathrm{a}}$ milk products & 0.05 & $-0.29 *$ \\
\hline Non-Keyhole ${ }^{\mathrm{a}}$ milk products & 0.08 & $0.21 *$ \\
\hline Cream and crème fraiche & 0.16 & $0.26 *$ \\
\hline Cheese & $0.34 *$ & $0.24 *$ \\
\hline Fast food and savoury bakery & 0.13 & 0.08 \\
\hline Pasta, rice, and food grain & 0.15 & -0.13 \\
\hline $\begin{array}{l}\text { Bread refined } \leq 5 \% \text { fibre } \\
\text { content }\end{array}$ & 0.10 & $0.31 *$ \\
\hline $\begin{array}{l}\text { Bread fibre-rich }>5 \% \text { fibre } \\
\text { content }\end{array}$ & $0.39 *$ & -0.13 \\
\hline Cereals & $0.27 *$ & -0.15 \\
\hline Sweet bakery & $0.22 *$ & $0.22 *$ \\
\hline Desserts & $0.25^{*}$ & 0.02 \\
\hline Sweet condiments & $0.29 *$ & 0.16 \\
\hline Sweets, candy, and chocolate & 0.11 & 0.14 \\
\hline Soups & 0.18 & -0.13 \\
\hline $\begin{array}{l}\text { Sauces, dressings, and condi- } \\
\text { ment }\end{array}$ & 0.18 & 0.05 \\
\hline Margarine & $0.36^{*}$ & $0.50 *$ \\
\hline Butter & 0.04 & 0.19 \\
\hline Vegetable oil & $0.28 *$ & -0.08 \\
\hline Juice & $0.28 *$ & -0.17 \\
\hline Coffee & 0.04 & 0.08 \\
\hline Tea & 0.18 & -0.10 \\
\hline Soda & 0.13 & 0.15 \\
\hline Alcoholic beverages & $0.28^{*}$ & $0.43^{*}$ \\
\hline
\end{tabular}

The content of each food group can be found in supplementary file 1 . The dietary patterns were derived with reduced rank regression analysis (RRR) on the total dietary sample $(n=753)$, producing an individual score for each participant

*Two factors from the RRR were translated into dietary patterns based on factor loading thresholds $\leq-0.20$ and $\geq 0.20$

${ }^{a}$ Keyhole is the Swedish National Food Agency-labelling scheme, which guides healthy food choices. For milk and yogurt to meet the criteria for the Keyhole, fat content must be limited to a maximum of $0.7 \%$, and for flavoured products there is an additional limit for sugars with a maximum of $9 \%$
Factor loadings in between -0.2 and 0.2 (close to 0 ) can be considered weak and do not explain the variation in the response variables well. The additional three factors were not examined further since they did not add to explaining the variation in the specified response variables (food group factor loadings were in between $\leq-0.20$ and $\geq 0.20$ for most food groups). Factor 1 loaded high on foods found in healthier dietary patterns (e.g., MeDi) such as vegetables, pulses, fruits, berries, fibre-rich bread, fish and seafood, and a higher adherence correlated strongest (of the two dietary patterns) with higher intakes of vitamin $\mathrm{C}, \mathrm{E}$, folate, fibre, and polyunsaturated fatty acids (Table 2). Factor 1 was, therefore, labelled the "healthy" dietary pattern (Table 1). Factor 2 loaded high on foods found in less healthy western style dietary patterns such as read meat and processed red meat, refined bread, full-fat dairy products and alcohol and low on vegetables, pulses, fruits and berries, and a higher adherence correlated strongest (of the two dietary patterns) with higher intakes of saturated fatty acids, alcohol, and with lower intakes of vitamin C, folate, and fibre (Table 2). Factor 2 was, therefore, labelled the "western" dietary pattern (Table 1).

\section{Dementia diagnosis}

Dementia was diagnosed at the examinations (1992-93, 2000-02, 2005, 2009, 2015-16) following the Diagnostic and Statistical Manual of Mental Disorders, Third edition, Revised criteria [52], using information from comprehensive neuropsychiatric examinations, a battery of neuropsychological tests and information from close informants, described in detail previously [34]. The same method was used at all examinations for comparability over time. Age of dementia onset was based on information from close informants,

Table 2 Correlations between extracted dietary pattern scores and response variables from the reduced rank regression analysis

\begin{tabular}{llc}
\hline & $\begin{array}{l}\text { Healthy } \\
\text { dietary pattern } \\
\text { (factor 1) }\end{array}$ & $\begin{array}{l}\text { Western } \\
\text { dietary pat- } \\
\text { tern } \\
\text { (factor 2) }\end{array}$ \\
\hline Response variables & & \\
Vitamin E (mg/day) & 0.67 & 0.13 \\
Vitamin C (mg/day) & 0.50 & -0.41 \\
Folate ( $\mu$ g/day) & 0.73 & -0.26 \\
Saturated fatty acids (g/day) & 0.45 & 0.60 \\
Polyunsaturated fatty acids (g/day) & 0.61 & 0.36 \\
Fibre (g/day) & 0.70 & -0.39 \\
Alcohol (g/day) & 0.21 & 0.40 \\
\hline
\end{tabular}

$p$ values for all correlations were $<0.0001$. The dietary patterns were derived with reduced rank regression analysis on the total dietary sample ( $n=753$ ), producing an individual score for each participant 
the examinations, or the Swedish inpatient register. If no information of age at dementia onset could be obtained, the midpoint between examinations (last examination without dementia to first examination with dementia) was used.

\section{Genotype data}

Genotyping was performed with the NeuroChip (Illumina) [53]. QC included the removal of participants due to any of the following: per-sample call rate $<98 \%$, sex mismatch, and excessive heterozygosity [FHET ( $\mathrm{F}$ coefficient estimate for assessing heterozygosity) outside \pm 0.2$]$. Samples were defined as non-European ancestral outliers, and removed, if their first two principal components (PCs) exceeded six standard deviations from the mean values of the European samples in the 1000 Genome global reference population. Closely related samples were removed based on pairwise PI_HAT (i.e., proportion of genome that are in identity-bydescent; calculated using -genome option in PLINK) $\geq 0.2$. Further, markers were excluded due to per-single-nucleotide polymorphism (SNP) call rate $<98 \%$, minor allele frequency (MAF) $<0.01$, and Hardy-Weinberg disequilibrium $(p<1 \times 10-6)$. The Sanger imputation service was used to impute post-QC, using the reference panel of Haplotype Reference Consortium data (HRC1.1) [18, 22]. The variants rs 7412 and rs 429358 (which define the $\varepsilon 2, \varepsilon 3$, and $\varepsilon 4$ alleles) in the $A P O E$ gene were also genotyped with the KASPar ${ }^{\circledR}$ PCR SNP genotyping system (LGC Genomics, Hoddesdon, Herts, UK) or by mini sequencing, as previously described in detail [54].

\section{Polygenic risk scores and $A P O E$ genotype}

AD-PRSs were generated using stage 1 of the most recent AD GWAS including clinically defined AD phenotypes [55]. SNPs were selected using LD clumping. The European ancestry samples from the 1000-genomes project were used as reference panel to remove variants in $\mathrm{LD}$, all variants $250 \mathrm{~kb}$ upstream and downstream of the top signal were removed $\left(R^{2}<0.001\right)$. All variants in the $A P O E$ region (chromosome 19, coordinates hg 19: 44,412,079 to $46,412,079)$ were removed. In this study, we created PRSs including variants that surpassed four $p$ value thresholds $(p<5 \mathrm{e}-8, p<1 \mathrm{e}-5, p<1 \mathrm{e}-3, p<1 \mathrm{e}-1)$, referred to as $5 \mathrm{e}-8$ AD-PRS (including 15 SNPs), 1e-5 AD-PRS (including 57 SNPs), 1e-3 AD-PRS (including 1333 SNPs), and 1e-1 ADPRS (including 13942 SNPs). All PRSs were calculated as the sum of the $\beta$-coefficient multiplied with the number (or dosage) of effect alleles of each SNP [18, 22]. The ADPRSs scores were divided into tertiles and participants were categorised as having either low, middle, or high risk. APOE genotype was divided into $\varepsilon 4$ carriers $(\varepsilon 4 / \varepsilon 2$, $\varepsilon 4 / \varepsilon 3$, or $\varepsilon 4 /$ $\varepsilon 4)$ and $\varepsilon 4$ non-carriers $(\varepsilon 2 / \varepsilon 2$, $\varepsilon 3 / \varepsilon 3$, or $\varepsilon 3 / \varepsilon 2)$.

\section{Potential confounders}

Information on potential confounders were obtained through semi-structured interviews and health examinations at baseline examinations (1992-93 or 2000-02). Confounders were chosen a priori based on previous literature. Sex, energy intake, birth year, educational level, physical activity level, smoking, body mass index (BMI,), hypertension, diabetes mellitus and serum cholesterol levels were considered potential confounders. Energy intake was measured as kcal/day and BMI as $\mathrm{kg} / \mathrm{m}^{2}$. Educational level was dichotomized into compulsory primary education $(\leq 6$ years for birth cohort $1922, \leq 7$ years for birth cohort 1930) versus more than that. Physical activity level was divided into three groups based on a modified Saltin-Grimby physical activity scale [56]: sedentary lifestyle (sedentary/low physical activity level), moderate physical activity level (low to moderate), or high activity level (moderate to high). Hypertension was defined as systolic blood pressure of $\geq 140 \mathrm{mmHg}$ and/or a diastolic blood pressure of $\geq 90 \mathrm{mmHg}$ (yes/no). Smoking was defined as either current smoker or non-smoker (never smoked or previous smoker). Diabetes mellitus was defined as a diagnosis told by a medical doctor, being on antidiabetic drugs, or having a venous blood glucose value of $\geq 11.1 \mathrm{mmol} / \mathrm{L}$ (yes/no). In the analyses including gene data, five principal components (PCs) were added as potential confounders to correct for population stratification (differences in allele frequencies due to genetic ancestry).

\section{Statistical analyses}

Chi-square and Mann-Whitney $U$ tests (nominal and ordinal variables) and Student's independent $t$ tests (continuous variables) were performed to compare characteristics between participants with and without incident dementia.

The interaction variables $A P O E \& 4$ (carrier or noncarrier)*healthy dietary pattern (factor score 1 ) and $A P O E$ $\varepsilon 4$ (carrier or non-carrier)*western dietary pattern (factor score 2) were calculated. The interaction variables AD-PRS (low, middle or high risk)*dietary pattern score (factor score 1) and AD-PRS (low, middle or high risk)*dietary pattern score (factor score 2) were calculated for all AD-PRSs (5e-8 AD-PRS*healthy dietary pattern, 1e-5 AD-PRS*healthy dietary pattern, 1e-3 AD-PRS*healthy dietary pattern, 1e-1 AD-PRS* healthy dietary pattern, 5e-8 AD-PRS*western dietary pattern, 1e-5 AD-PRS*western dietary pattern, 1e-3 AD-PRS*western dietary pattern and 1e-1 AD-PRS*western dietary pattern).

Cox regression analyses were performed in two models with the healthy and western dietary pattern scores (factor scores 1 and 2) as independent variables and incident dementia as the dependent variable. In model 1, the analyses were adjusted for sex and birth year. In model 2 , the analyses 
were adjusted for sex, birth year, energy intake, BMI, serum cholesterol, diabetes, hypertension, smoking, education, and physical activity level. Further, Cox regression analyses were performed with the interaction variables as independent variables and incident dementia as the dependent variable. All interaction analyses were performed in two models. In model 1, the analyses were adjusted for sex and birth year. In model 2, the analyses were adjusted for sex, birth year, energy intake, BMI, serum cholesterol, diabetes, hypertension, smoking, education, and physical activity level, and 5 PCs to adjust for population stratification. Similar to other studies, we chose a $p$ value threshold of $<0.1$ to detect an interaction $[26,28,29]$. To facilitate interpretation of identified interactions and interaction models, effect values for the prediction scores were shown for each genetic group separately.

The time variable in all the Cox regression analyses was calculated as time in years from baseline examination (1992-93 or 2000-02) to either age at dementia diagnosis, age at death or time to end of study (Dec 31, 2016, for those with last examination year 2015-16, and Dec 31, 2012, for those with register data until 2012). Cox model proportional hazard assumptions were verified with Schoenfeld residuals.

The statistical analyses were performed using IBM SPSS STATISTICS 24. R programming versions 3.6.0 were used to test Cox model proportional hazard assumptions.

\section{Results}

Characteristics of the participants who were free from dementia at baseline and had both dietary and genetic data are presented for the total sample and stratified by incident dementia, yes/no in Table 3. During the mean follow-up time of 12.8 years (SD 4.5 years, 7685.5 person-years), 125 participants developed dementia. The mean age of dementia onset was 80.2 years (SD 4.9). There were no significant differences in characteristics between those that developed dementia and those that did not, except for a higher BMI (26 vs. 27) and a higher adherence to the healthy dietary pattern among those that did not develop dementia, and a higher percentage of $A P O E \varepsilon 4$ carriers among those that developed dementia (26 vs. $40 \%)$.

In the total population, we found no associations between adherence to the dietary patterns and incident dementia in either model 1 or model 2 (Table 4).

Interactions were observed between adherence to the dietary patterns and $A P O E \varepsilon 4$ status in relation to incident dementia (interaction $p$ value threshold of $<0.1$ ) (Table 5). For the healthy dietary pattern, this interaction was found in model 1 , but not in the fully adjusted model 2 . For the western dietary pattern, there was an interaction in both model 1 and the fully adjusted model 2 (Table 5).
$A P O E \& 4$ non-carriers with a higher adherence to the healthy dietary pattern had a reduced risk of dementia in model 1 (HR $0.79 ; 95 \%$ CI $0.65-0.95$ ) and in the fully adjusted model 2 (HR 0.77; 95\% CI 0.61-0.98), but no such associations were found among APOE $\varepsilon 4$ carriers (Table 6). There was an association between the western dietary pattern and an increased risk of dementia among APOE $\varepsilon 4$ carriers in the fully adjusted model 2 (HR 1.37; 95\% CI 1.05-1.78), but not in model 1 (HR 1.28; 95\% CI 0.99-1.66). There was no association between the western dietary pattern and an increased risk of dementia among $A P O E \varepsilon 4$ noncarriers (Table 6).

No interactions were found between the AD-PRSs (divided into tertiles of low, middle, or high risk) and the dietary patterns (healthy and western) in relation to incident dementia (Table 5).

\section{Discussion}

We found interactions between dietary patterns and $A P O E$ $\varepsilon 4$ status in relation to incident dementia among 70-yearolds in a population-based sample followed on average for 13 years. Among APOE $\varepsilon 4$ non-carriers, we found an association between higher adherence to a healthy dietary pattern and reduced risk of incident dementia. This association was not observed among $\varepsilon 4$ carriers. However, there was an association between higher adherence to a less healthy western dietary pattern and an increased risk of dementia among $\varepsilon 4$ carriers, but not among $\varepsilon 4$ non-carriers. There were no interactions between the AD-PRSs and the dietary patterns in relation to incident dementia.

We could not find other studies that investigated interactions between different dietary patterns and both AD-PRS scores and $A P O E \& 4$ status in relation to incident dementia. Some studies have, however, investigated interactions between single genetic variants (usually $A P O E \varepsilon 4$ ) and either single foods or nutrients, or dietary patterns, in relation to either dementia or cognitive function [25-27, 30, 31, 57]. The PREDIMED-NAVARRA intervention study (mean age 67) found an interaction between $C L U$ and MeDi in relation to cognitive function, but no other gene-MeDi interactions (CR1, PICALM, APOE) were found [25]. A study from the Rush Memory and Aging Project found a marginally statistically significant interaction between the MIND (Mediterranean-DASH Intervention for Neurodegenerative Delay) diet and $A P O E \& 4$ in relation to AD [23]. Similar to our study, those two studies found higher protective effects of a healthy dietary pattern among those with a favourable genetic predisposition $[23,25]$. In our study, we did not find any interactions between the AD-PRSs and the dietary patterns in relation to incident dementia. One previous study has investigated the interplay between AD-PRS and dietary 
Table 3 Characteristics of participants with dietary and genetic data

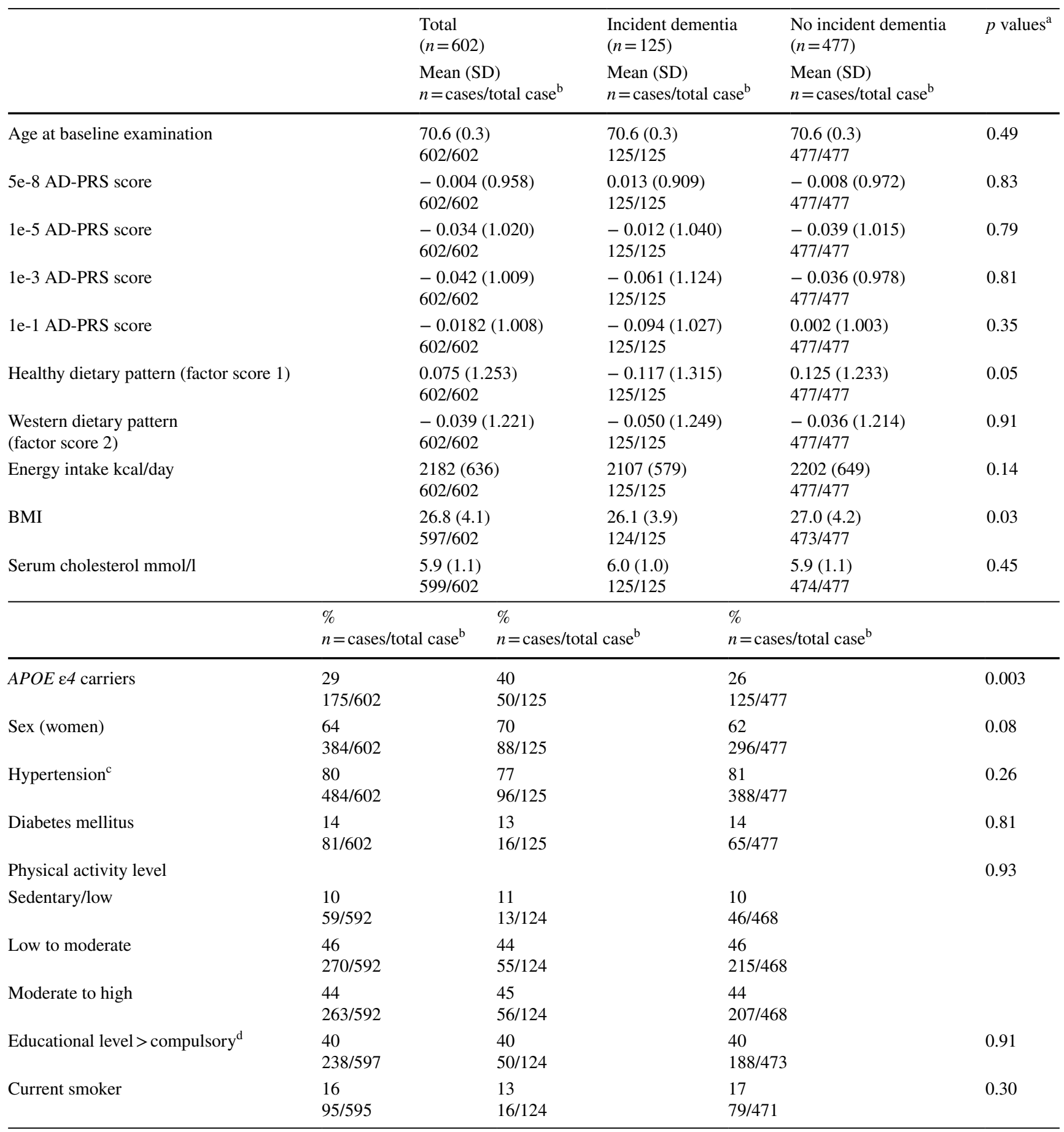

${ }^{\mathrm{a}} p$ values for comparisons between those that developed dementia and those that did not

${ }^{\mathrm{b}}$ Total number of cases are presented for all characteristics since there are missing data for some of the variables

${ }^{\mathrm{c}}$ Hypertension was defined as systolic blood pressure of $\geq 140 \mathrm{mmHg}$ and/or a diastolic blood pressure of $\geq 90 \mathrm{mmHg}$

${ }^{\mathrm{d}}$ More than 6 years for birth cohort 1922 and more than 7 years for birth cohort 1930

patterns in relation to cognitive function [26]. They found that poorer diet quality interacted with a 12 SNP AD-PRS (including $A P O E$ ) in relation to lower scores on verbal fluency among African Americans (mean age 57) [26].
However, their results are somewhat hard to compare with ours since we used non- $A P O E$ AD-PRSs, and dementia was the outcome. The Three-city cohort study and the Cardiovascular Health Cognition study found interactions between fish 
Table 4 Associations between adherence to the dietary patterns and incident dementia in the total sample

\begin{tabular}{|c|c|c|c|c|c|c|}
\hline \multirow{3}{*}{$\begin{array}{l}\text { Dietary pat- } \\
\text { terns }\end{array}$} & \multirow{2}{*}{\multicolumn{2}{|c|}{$\frac{\text { Model }^{\mathrm{a}}}{\text { Dementia } n=125 / 602^{\mathrm{b}}}$}} & \multirow[t]{3}{*}{$p$ value } & \multicolumn{2}{|c|}{ Model $2^{\mathrm{a}}$} & \multirow[t]{3}{*}{$p$ value } \\
\hline & & & & \multicolumn{2}{|c|}{ Dementia $n=121 / 573^{b}$} & \\
\hline & HR & $95 \% \mathrm{CI}$ & & HR & $95 \% \mathrm{CI}$ & \\
\hline $\begin{array}{l}\text { Healthy (fac- } \\
\text { tor } 1 \text { ) }\end{array}$ & 0.87 & $0.75 ; 1.02$ & 0.08 & 0.83 & $0.67 ; 1.03$ & 0.09 \\
\hline $\begin{array}{l}\text { Western (fac- } \\
\text { tor } 2 \text { ) }\end{array}$ & 1.04 & $0.89 ; 1.21$ & 0.62 & 1.06 & $0.90 ; 1.25$ & 0.48 \\
\hline
\end{tabular}

HR and 95\% CI estimated using a Cox proportional hazards model with follow-up time (years) as the time scale

${ }^{a}$ Model 1 is adjusted for sex and birth year. Model 2 is adjusted for sex, birth year, BMI, energy intake, serum cholesterol level, hypertension, diabetes, physical activity level, educational level, and smoking status

${ }^{\mathrm{b}}$ Dementia events/total cases. Those with missing data were excluded in model 2 ( $n=29$ with missing data, $n=5$ for BMI, $n=3$ for serum cholesterol, $n=5$ for education, $n=10$ for physical activity level and $n=7$ for smoking)

consumption and $A P O E \varepsilon 4$ in relation to dementia among older adults (age $>65$ years), and that consumption of fish was associated with reduced risk among $\varepsilon 4$ non-carriers, but not among $\varepsilon 4$ carriers $[27,57]$. The Three-City cohort study also investigated interactions between n-3 fatty acids, a less healthy dietary pattern and $A P O E \varepsilon 4$ in relation to dementia, but no interactions were found [27]. Another study from the Rush Memory and Aging Project found interactions between n-3 fatty acids, seafood and APOE $\varepsilon 4$ in relation to cognitive function among older adults (mean age 84 years), and that consumption of seafood and n-3 fatty acids was associated with slower global cognitive decline among $\varepsilon 4$ carriers, but not among $\varepsilon 4$ non-carriers [30]. An observational study with pooled participants from the Three-City study and 4 US cohorts (Nurses' Health study, Women's health study, Chicago Health and Aging project and Rush Memory and Aging projects) found no interactions between fish consumption and $A P O E \& 4$ and 11 other $\mathrm{AD}$-related genes in relation to cognitive decline among older adults (age $>65$ years) [31]. Methodological differences between studies in determining genetic risk, cognitive outcome, age, dietary intake, synergistic effects of foods and nutrients, and differences in food choices and consumption levels could be part of the explanation to why results differ between studies [58].

The dietary patterns derived from the RRR analysis in our study resembles dietary patterns previously associated with dementia risk $[3,8,11]$. The healthy dietary pattern loaded high on foods found in dietary patterns that have been associated with reduced risk (i.e., MeDi) [59], and a higher adherence to the healthy pattern correlated positively (strongest of the two dietary patterns) with the potentially risk reducing nutrients included as response variables in the RRR analysis (fibre, folate, vitamin E and C, and polyunsaturated fatty acids) [3, 41-44]. The western pattern loaded high on foods found in dietary patterns associated with increased risk of dementia [8], and a higher adherence correlated positively with saturated fat intake, and negatively with vitamin $\mathrm{C}$, folate, and fibre intake. Both dietary patterns in our study correlated with higher alcohol intake, but the correlation was stronger with the western dietary pattern, indicating that alcohol may be a more detrimental factor in the western pattern [46]. Even though the healthy pattern in our study also contained food groups that could be included in a western pattern (red meat, desserts, and sweet bakery), we did find an association between higher adherence and reduced risk of dementia among APOE $\varepsilon 4$ non-carriers. A reason for that may be that a healthy diet may attenuate the adverse effects of a western diet [13].

Mechanisms underlying potential APOE-diet interactions in relation to dementia risk may involve altered metabolism of n-3 fatty acids, glucose or ketones, impaired transport of fatty acids and cholesterol, or modification of other risk factors where $A P O E$ status is involved $[6,28]$. The $A P O E$ $\varepsilon 4$ allele has been associated with cardiovascular conditions such as hypercholesterolemia, hypertriglyceridemia (lipid metabolism), increased insulin resistance, enhanced response to inflammation (chronic inflammation), and increased atherosclerosis (vascular system) [60], which may provide links between diet and $A P O E \& 4$ carriership in relation to dementia risk since several of these cardiovascular conditions also are affected by dietary factors $[5,6$, $44,61,62]$. It might be that the effect of $A P O E \varepsilon 4$ carriership diminishes the effect of a healthy diet on dementia risk by intervening at specific sites in the pathogenetic process, e.g., related to cholesterol metabolism. It has also been suggested that diets rich in refined carbohydrates could promote dementia and AD through insulin resistance [63], especially among $A P O E \varepsilon 4$ carriers [64]. A study from the from the French Three-City Study found an interaction between $A P O E \& 4$ and high glycemic load (GL) afternoon snacks, 
Table 5 Interactions between genetic risk factors and dietary patterns in relation to incident dementia

\begin{tabular}{|c|c|c|c|c|c|c|}
\hline \multirow[t]{3}{*}{ Interaction models } & \multirow{2}{*}{\multicolumn{2}{|c|}{$\begin{array}{l}\text { Model } 1^{\mathrm{a}} \\
\text { Dementia } \\
n=125 / 602^{\mathrm{b}}\end{array}$}} & \multirow[t]{3}{*}{$p$ value } & \multirow{2}{*}{\multicolumn{2}{|c|}{$\begin{array}{l}{\text { Model } 2^{\mathrm{a}}} \\
\text { Dementia } \\
n=121 / 573^{\mathrm{b}}\end{array}$}} & \multirow[t]{3}{*}{$p$ value } \\
\hline & & & & & & \\
\hline & HR & $\mathrm{CI}$ & & HR & $\mathrm{CI}$ & \\
\hline$A P O E \varepsilon 4$ *healthy dietary pattern & 1.29 & $0.96 ; 1.74$ & 0.09 & 1.13 & $0.82 ; 1.54$ & 0.47 \\
\hline Healthy dietary pattern & 0.79 & $0.65 ; 0.95$ & 0.01 & 0.77 & $0.61 ; 0.98$ & 0.03 \\
\hline$A P O E \varepsilon 4$ status & 1.83 & $1-27 ; 2.63$ & 0.001 & 2.0 & $1.37 ; 2.91$ & 0.0003 \\
\hline$A P O E \varepsilon 4 *$ western dietary pattern & 1.31 & $0.96 ; 1.79$ & 0.09 & 1.38 & $1.01 ; 1.89$ & 0.05 \\
\hline Western dietary pattern & 0.98 & $0.81 ; 1.18$ & 0.81 & 0.99 & $0.81 ; 1.21$ & 0.92 \\
\hline$A P O E \& 4$ status & 1.87 & $1.31 ; 2.68$ & 0.001 & 2.06 & $1.42 ; 3.00$ & 0.0001 \\
\hline 5e-8 AD-PRS*healthy dietary pattern & 0.91 & $0.77 ; 1.08$ & 0.29 & 0.97 & $0.81 ; 1.16$ & 0.70 \\
\hline Healthy dietary pattern & 1.05 & $0.72 ; 1.52$ & 0.81 & 0.89 & $0.58 ; 1.37$ & 0.60 \\
\hline 5e-8 AD-PRS & 0.98 & $0.79 ; 1.22$ & 0.87 & 0.97 & $0.77 ; 1.21$ & 0.77 \\
\hline 1e-5 AD-PRS*healthy dietary pattern & 0.92 & $0.78 ; 1.10$ & 0.36 & 1.01 & $0.84 ; 1.22$ & 0.90 \\
\hline Healthy dietary pattern & 1.03 & $0.70 ; 1.52$ & 0.88 & 0.82 & $0.52 ; 1.28$ & 0.37 \\
\hline 1e-5 AD-PRS & 1.09 & $0.88 ; 1.36$ & 0.44 & 1.12 & $0.89 ; 1.40$ & 0.35 \\
\hline 1e-3 AD-PRS*healthy dietary pattern & 1.05 & $0.88 ; 1.26$ & 0.59 & 1.02 & $0.84 ; 1.23$ & 0.86 \\
\hline Healthy dietary pattern & 0.79 & $0.54 ; 1.16$ & 0.23 & 0.80 & $0.53 ; 1.23$ & 0.31 \\
\hline 1e-3 AD-PRS & 1.05 & $0.85 ; 1.30$ & 0.65 & 1.04 & $0.84 ; 1.30$ & 0.70 \\
\hline 1e-1 AD-PRS*healthy dietary pattern & 0.99 & $0.82 ; 1.18$ & 0.88 & 0.95 & $0.78 ; 1.14$ & 0.56 \\
\hline Healthy dietary pattern & 0.90 & $0.61 ; 1.31$ & 0.57 & 0.92 & $0.61 ; 1.39$ & 0.70 \\
\hline 1e-1 AD-PRS & 0.94 & $0.76 ; 1.17$ & 0.59 & 0.98 & $0.78 ; 1.23$ & 0.88 \\
\hline 5e-8 AD-PRS*western dietary pattern & 1.10 & $0.91 ; 1.32$ & 0.32 & 1.07 & $0.89 ; 1.30$ & 0.47 \\
\hline Western dietary pattern & 0.87 & $0.58 ; 1.28$ & 0.47 & 0.93 & $0.62 ; 1.39$ & 0.72 \\
\hline 5e-8 AD-PRS & 1.00 & $0.81 ; 1.24$ & 0.99 & 0.98 & $0.79 ; 1.23$ & 0.88 \\
\hline 1e-5 AD-PRS*western dietary pattern & 1.05 & $0.87 ; 1.27$ & 0.62 & 0.99 & $0.82 ; 1.20$ & 0.96 \\
\hline Western dietary pattern & 0.95 & $0.63 ; 1.42$ & 0.79 & 1.07 & $0.71 ; 1.63$ & 0.74 \\
\hline 1e-5 AD-PRS & 1.11 & $0.90 ; 1.39$ & 0.33 & 1.12 & $0.90 ; 1.41$ & 0.32 \\
\hline 1e-3 AD-PRS*western dietary pattern & 0.96 & $0.80 ; 1.16$ & 0.68 & 0.98 & $0.81 ; 1.18$ & 0.83 \\
\hline Western dietary pattern & 1.12 & $0.76 ; 1.65$ & 0.57 & 1.11 & $0.74 ; 1.65$ & 0.62 \\
\hline 1e-3 AD-PRS & 1.05 & $0.85 ; 1.30$ & 0.65 & 1.04 & $0.83 ; 1.30$ & 0.72 \\
\hline 1e-1 AD-PRS*western dietary pattern & 1.06 & $0.88 ; 1.28$ & 0.56 & 1.04 & $0.85 ; 1.26$ & 0.71 \\
\hline Western dietary pattern & 0.93 & $0.63 ; 1.38$ & 0.72 & 0.99 & $0.65 ; 1.50$ & 0.96 \\
\hline 1e-1 AD-PRS & 0.95 & $0.77 ; 1.18$ & 0.65 & 1.00 & $0.79 ; 1.25$ & 0.97 \\
\hline
\end{tabular}

HR and 95\% CI estimated using a Cox proportional hazards model with follow-up time (years) as the time scale. $A P O E \& 4$ status are divided into carriers/non-carriers. The AD-PRSs are divided into tertiles of low/ middle or high risk. Factor score 1 is labelled the "healthy" dietary pattern and factor score 2 is labelled the "western" dietary pattern

${ }^{a}$ Model 1 is adjusted for sex and birth year. Model 2 is adjusted for sex, birth year, BMI, energy intake, serum cholesterol level, hypertension, diabetes, physical activity level, educational level, smoking, and five principal components (PCs) to correct for population stratification

${ }^{\mathrm{b}}$ Dementia events/total cases. Those with missing data were excluded in model 2 ( $n=29$ with missing data, $n=5$ for BMI, $n=3$ for serum cholesterol, $n=5$ for education, $n=10$ for physical activity level and $n=7$ for smoking) and that high afternoon-snack GL was associated with increased dementia and AD risk in $A P O E-\varepsilon 4$ carriers [64]. However, mechanisms remain elusive and there could be other explanations for an interplay between diet and $A P O E$ $\varepsilon 4$ status in relation to dementia. Protective effects from diet might not compensate the higher genetic risk associated with $A P O E \varepsilon 4$ carriership, which could explain why we only found risk reducing effects of a healthy dietary pattern among $A P O E \& 4$ non-carriers. However, $A P O E \varepsilon 4$ carriers could potentially still be vulnerable for detrimental effects of less healthy dietary patterns [65], as our results suggest. 
Table 6 Associations between adherence to the dietary patterns and incident dementia among $A P O E$ \&4 carriers and $A P O E \& 4$ non-carriers

\begin{tabular}{|c|c|c|c|c|c|c|}
\hline & \multicolumn{2}{|c|}{ Model $1^{\mathrm{a}}$} & \multirow[t]{3}{*}{$p$ value } & \multicolumn{2}{|c|}{ Model $2^{\mathrm{a}}$} & \multirow[t]{3}{*}{$p$ value } \\
\hline & \multicolumn{2}{|c|}{$\overline{\text { Dementia } n=125 / 602^{b}}$} & & \multicolumn{2}{|c|}{ Dementia $n=121 / 573^{b}$} & \\
\hline & HR & $\mathrm{CI}$ & & HR & CI & \\
\hline \multicolumn{7}{|l|}{ Healthy dietary pattern } \\
\hline$A P O E \& 4$ non-carriers & 0.79 & $0.65 ; 0.95$ & 0.01 & 0.77 & $0.61 ; 0.98$ & 0.03 \\
\hline$A P O E \& 4$ carriers & 1.02 & $0.80 ; 1.30$ & 0.89 & 0.86 & $0.63 ; 1.18$ & 0.35 \\
\hline \multicolumn{7}{|l|}{ Western dietary pattern } \\
\hline$A P O E \varepsilon 4$ non-carriers & 0.98 & $0.81 ; 1.18$ & 0.81 & 0.99 & $0.81 ; 1.21$ & 0.92 \\
\hline$A P O E \& 4$ carriers & 1.28 & $0.99 ; 1.66$ & 0.06 & 1.37 & $1.05 ; 1.78$ & 0.02 \\
\hline
\end{tabular}

HR and 95\% CI estimated using a Cox proportional hazards model with follow-up time (years) as the time scale. To facilitate interpretation of identified interactions between dietary patterns*APOE $\varepsilon 4$ in relation to incident dementia, separate effect values for the prediction scores are shown for $A P O E \& 4$ carriers and $A P O E \varepsilon 4$ non-carriers

${ }^{a}$ Model 1 is adjusted for sex and birth year. Model 2 is adjusted for sex, birth year, BMI, energy intake, serum cholesterol level, hypertension, diabetes, physical activity level, educational level, and smoking and five principal components (PCs) to correct for population stratification

${ }^{\mathrm{b}}$ Dementia events/total cases. Those with missing data were excluded in model 2 ( $n=29$ with missing data, $n=5$ for BMI, $n=3$ for serum cholesterol, $n=5$ for education, $n=10$ for physical activity level and $n=7$ for smoking)

\section{Strengths and limitations}

This is one of few studies that have investigated interactions between different dietary patterns and both $A P O E \varepsilon 4$ status and non- $A P O E \& 4$ PRSs in relation to dementia. Strengths of this study are the systematically selected population-based sample, the comprehensive examinations and long follow-up time. The neuropsychiatric examinations were performed by psychiatric nurses and the dementia diagnoses were set in accordance with established diagnostic criteria. The diet history method in this study is validated, and the dietary interviews were performed by registered dietitians, which may reduce misreporting of dietary intake (e.g., recall, over-under reporting), common in dietary examinations $[35,66]$. Another strength was the use of the RRR analysis to derive dietary patterns, since it considers both a priori knowledge about dietary factors related to dementia and explores dietary patterns that exist in this population.

The outcome in this study was incident dementia, which may include subtypes of dementia that are not as strongly linked to the genetic risk factors as AD. This could potentially have attenuated the results. It was not possible to perform sub-analyses since there were no data available for subtypes of dementia in the 2015-16 examination. However, in Swedish populations, approximately two-thirds of those with dementia have $\mathrm{AD}[67,68]$. Moreover, the sample size may be too small to detect a potential interaction between the AD-PRSs and diet in relation to dementia since the effect of the AD-PRSs is not as strong as APOE \&4. We found an interaction between the western dietary pattern and APOE $\varepsilon 4$ status in relation to incident dementia in both adjusted models. For the healthy dietary pattern, we found an interaction in the model that was adjusted for sex and birth year, but not in the fully adjusted model. The results should, therefore, be interpreted with caution. Dietary intake may change during life, and since we do not have dietary data before or after the age of 70, we cannot determine potential effects of dietary intake earlier or later in life. Moreover, the analyses were performed on a Swedish population, and the possibility to generalize the results to non-Caucasian populations is limited.

\section{Conclusions}

The results of this study suggest that there is an interplay between $A P O E \& 4$ status and adherence to dietary patterns in relation to incident dementia. Higher adherence to a healthy dietary pattern was associated with a reduced risk of dementia among $\varepsilon 4$ non-carriers, but not among $\varepsilon 4$ carriers. A higher adherence to a western dietary pattern was associated with increased risk of dementia among $\varepsilon 4$ carriers, but not among $\varepsilon 4$ non-carriers. This suggests that diet may play a role and that the effects of risk or risk reducing dietary patterns could differ depending on $\varepsilon 4$ carriership. These findings could be of importance for precision nutrition in dementia prevention strategies and for future intervention studies investigating the effect of dietary patterns in relation to dementia incidence.

Supplementary Information The online version contains supplementary material available at https://doi.org/10.1007/s00394-021-02688-9. 
Acknowledgements The authors thank the participants of the Gothenburg H70 birth cohort studies, including the Population Study of Women in Gothenburg.

Author contributions JS and AZ: conception and design of the study; JS: drafting and writing the article; IS, HZ, KB, ER, SK, LL, HW, MMF, JN, and AZ: acquisition of data; JS, OW, AZ, and IS: analysis and interpretation of data; IS, HZ, KB, ER, SK, LL, HW, MMF, JN, $\mathrm{AZ}$, and OW: revising the article critically for important intellectual content; AZ: supervision. All authors read and approved the final manuscript.

Funding Open access funding provided by University of Gothenburg. SK was financed by grants from the Swedish state under the agreement between the Swedish government and the county councils, the ALF-agreement (ALFGBG-81392, ALF GBG-771071). The Alzheimerfonden (AF-842 471, AF-737641, AF-939825). The Swedish Research Council (2019-02075), Stiftelsen Demensfonden, Stiftelsen Hjalmar Svenssons Forskningsfond, Stiftelsen Wilhelm och Martina Lundgrens vetenskapsfond. HZ is a Wallenberg Scholar supported by grants from the Swedish Research Council (2018-02532), the European Research Council (681712), Swedish State Support for Clinical Research (ALFGBG-720931), the Alzheimer Drug Discovery Foundation (ADDF), USA (201809-2016862), the AD Strategic Fund and the Alzheimer's Association (ADSF-21-831376-C, ADSF-21-831381-C and ADSF-21-831377-C), the Olav Thon Foundation, the Erling-Persson Family Foundation, Stiftelsen för Gamla Tjänarinnor, Hjärnfonden, Sweden (FO2019-0228), the European Union's Horizon 2020 research and innovation programme under the Marie Skłodowska-Curie grant agreement No 860197 (MIRIADE), and the UK Dementia Research Institute at UCL. IS was financed by grants from the Swedish state under the agreement between the Swedish government and the county councils, the ALF-agreement (ALF 716681), Stena Foundation, Swedish Research Council (11267, 2005-8460, 2007-7462, 2012-5041, 2015-02830, 2019-01096, 2013-8717, NEAR 2017-00639), Swedish Research Council for Health, Working Life and Wellfare (2004-0145, 2006-0596, 2008-1111, 2010-0870, 2013-1202, 2018-00471, 20012646, 2003-0234, 2004-0150, 2006-0020, 2008-1229, 2012-1138, AGECAP 2013-2300, 2013-2496), Konung Gustaf V:s och Drottning Victorias Frimurarestiftelse, Hjärnfonden (FO2014-0207, FO20160214, FO2018-0214, FO2019-0163, FO2020-0235), Alzheimerfonden (AF-554461, AF-647651, AF-743701, AF-844671, AF-930868, AF-940139), Eivind och Elsa K:son Sylvans stiftelse, The Alzheimer's Association Zenith Award (ZEN-01-3151), The Alzheimer's Association Stephanie B. Overstreet Scholars (IIRG-00-2159), The Bank of Sweden Tercentenary Foundation, Stiftelsen Söderström-Königska Sjukhemmet, Stiftelsen för Gamla Tjänarinnor, Handlanden Hjalmar Svenssons Forskningsfond, KB is supported by the Swedish Research Council (2017-00915), the Alzheimer Drug Discovery Foundation (ADDF), USA (RDAPB-201809-2016615), the Swedish Alzheimer Foundation (AF-742881), Hjärnfonden, Sweden (FO2017-0243), the Swedish state under the agreement between the Swedish government and the County Councils, the ALF-agreement (ALFGBG-715986), the European Union Joint Program for Neurodegenerative Disorders (JPND2019-466-236), and the National Institute of Health (NIH), USA (grant 1R01AG068398-01). AZ was supported by the Swedish Alzheimer Foundation (AF-930582, AF-646061, AF-741361, AF-939988), Stiftelsen Demensfonden, Magnus Bergvalls Stiftelse, Stiftelsen för Gamla Tjänarinnor, and Stiftelsen Hjalmar Svenssons Forskningsfond. JS was supported by Stiftelsen Hjalmar Svenssons Forskningsfond.

Availability of data and materials The datasets used and/or analysed during the current study are available from the corresponding author on reasonable request.
Code availability Not applicable.

\section{Declarations}

Conflict of interest On behalf of all authors, the corresponding author states that there is no conflict of interest. SK has been consultant for Geras Solutions, unrelated to the findings in this manuscript. HZ has served at scientific advisory boards for Eisai, Denali, Roche Diagnostics, Wave, Samumed, Siemens Healthineers, Pinteon Therapeutics, Nervgen, AZTherapies and $\operatorname{CogRx}$, has given lectures in symposia sponsored by Cellectricon, Fujirebio, Alzecure and Biogen, and is a co-founder of Brain Biomarker Solutions in Gothenburg AB (BBS), which is a part of the GU Ventures Incubator Program (outside submitted work). KB has served as a consultant, at advisory boards, or at data monitoring committees for Abcam, Axon, Biogen, JOMDD/ Shimadzu. Julius Clinical, Lilly, MagQu, Novartis, Roche Diagnostics, and Siemens Healthineers, and is a co-founder of Brain Biomarker Solutions in Gothenburg AB (BBS), which is a part of the GU Ventures Incubator Program, all outside the submitted work.

Ethical approval Ethical approval was obtained from the Ethics Committee for Medical Research in Gothenburg, reference numbers 179-92, S22700, S37799, Ö40299 and S06901.

Consent to participate The tenets of the Declaration of Helsinki were followed, and informed consent was obtained from all participants.

Consent for publication Not applicable.

Open Access This article is licensed under a Creative Commons Attribution 4.0 International License, which permits use, sharing, adaptation, distribution and reproduction in any medium or format, as long as you give appropriate credit to the original author(s) and the source, provide a link to the Creative Commons licence, and indicate if changes were made. The images or other third party material in this article are included in the article's Creative Commons licence, unless indicated otherwise in a credit line to the material. If material is not included in the article's Creative Commons licence and your intended use is not permitted by statutory regulation or exceeds the permitted use, you will need to obtain permission directly from the copyright holder. To view a copy of this licence, visit http://creativecommons.org/licenses/by/4.0/.

\section{References}

1. Livingston G, Huntley J, Sommerlad A, Ames D, Ballard C, Banerjee $S$ et al (2020) Dementia prevention, intervention, and care: 2020 report of the Lancet Commission. Lancet (London, England). 396:413-446. https://doi.org/10.1016/S0140-6736(20) 30367-6

2. Lourida I, Hannon E, Littlejohns TJ, Langa KM, Hyppönen E, Kuzma E et al (2019) Association of lifestyle and genetic risk with incidence of dementia. JAMA 322:430-437. https://doi.org/ 10.1001/jama.2019.9879

3. Scarmeas N, Anastasiou CA, Yannakoulia M (2018) Nutrition and prevention of cognitive impairment. Lancet Neurol 17:1006-1015. https://doi.org/10.1016/s1474-4422(18)30338-7

4. Cao L, Tan L, Wang HF, Jiang T, Zhu XC, Lu H et al (2016) Dietary patterns and risk of dementia: a systematic review and meta-analysis of cohort studies. Mol Neurobiol 53:6144-6154. https://doi.org/10.1007/s12035-015-9516-4

5. Barberger-Gateau P, Lambert J-C, Féart C, Pérès K, Ritchie K, Dartigues J-F et al (2013) From genetics to dietetics: the 
contribution of epidemiology to understanding Alzheimer's disease. J Alzheimers Dis 33:S457-S463

6. Yassine HN, Finch CE (2020) APOE alleles and diet in brain aging and Alzheimer's disease. Front Aging Neurosci 12:150. https://doi.org/10.3389/fnagi.2020.00150

7. Solfrizzi V, Custodero C, Lozupone M, Imbimbo BP, Valiani V, Agosti P et al (2017) Relationships of dietary patterns, foods, and micro- and macronutrients with Alzheimer's disease and late-life cognitive disorders: a systematic review. J Alzheimers Dis 59:815-849. https://doi.org/10.3233/JAD-170248

8. Samadi M, Moradi S, Moradinazar M, Mostafai R, Pasdar Y (2019) Dietary pattern in relation to the risk of Alzheimer's disease: a systematic review. Neurol Sci 40:2031-2043. https:// doi.org/10.1007/s10072-019-03976-3

9. Lourida I, Soni M, Thompson-Coon J, Purandare N, Lang IA, Ukoumunne OC et al (2013) Mediterranean diet, cognitive function, and dementia: a systematic review. Epidemiology 24:479-489. https://doi.org/10.1097/EDE.0b013e3182944410

10. Petersson SD, Philippou E (2016) Mediterranean diet, cognitive function, and dementia: a systematic review of the evidence. Adv Nutr (Bethesda, Md). 7:889-904. https://doi.org/10.3945/ an.116.012138

11. van de Rest O, Berendsen AA, Haveman-Nies A, de Groot LC (2015) Dietary patterns, cognitive decline, and dementia: a systematic review. Adv Nutr (Bethesda, Md). 6:154-168. https:// doi.org/10.3945/an.114.007617

12. Valls-Pedret C, Sala-Vila A, Serra-Mir M, Corella D, de la Torre R, Martínez-González M et al (2015) Mediterranean diet and age-related cognitive decline: a randomized clinical trial. JAMA Intern Med 175:1094-1103. https://doi.org/10.1001/jamaintern med.2015.1668

13. Shakersain B, Santoni G, Larsson SC, Faxén-Irving G, Fastbom J, Fratiglioni L et al (2016) Prudent diet may attenuate the adverse effects of Western diet on cognitive decline. Alzheimers Dement 12:100-109. https://doi.org/10.1016/j.jalz.2015.08.002

14. van der Lee SJ, Wolters FJ, Ikram MK, Hofman A, Ikram MA, Amin $\mathrm{N}$ et al (2018) The effect of APOE and other common genetic variants on the onset of Alzheimer's disease and dementia: a community-based cohort study. Lancet Neurol 17:434444. https://doi.org/10.1016/s1474-4422(18)30053-x

15. Lambert JC, Ibrahim-Verbaas CA, Harold D, Naj AC, Sims R, Bellenguez C et al (2013) Meta-analysis of 74,046 individuals identifies 11 new susceptibility loci for Alzheimer's disease. Nat Genet 45:1452-1458. https://doi.org/10.1038/ng.2802

16. Chasioti D, Yan J, Nho K, Saykin AJ (2019) Progress in polygenic composite scores in Alzheimer's and other complex diseases. Trends Genet 35:371-382. https://doi.org/10.1016/j.tig. 2019.02.005

17. Licher S, Ahmad S, Karamujić-Čomić H, Voortman T, Leening MJG, Ikram MA et al (2019) Genetic predisposition, modifiable-risk-factor profile and long-term dementia risk in the general population. Nat Med 25:1364-1369. https://doi.org/10. 1038/s41591-019-0547-7

18. Najar J, van der Lee SJ, Joas E, Wetterberg H, Hardy J, Guerreiro R et al (2021) Polygenic risk scores for Alzheimer's disease are related to dementia risk in APOE $\varepsilon 4$ negatives. Alzheimers Dement (Amst) 13:e12142. https://doi.org/10.1002/dad2. 12142

19. Scelsi MA, Khan RR, Lorenzi M, Christopher L, Greicius MD, Schott JM et al (2018) Genetic study of multimodal imaging Alzheimer's disease progression score implicates novel loci. Brain 141:2167-2180. https://doi.org/10.1093/brain/awy141

20. Escott-Price V, Myers A, Huentelman M, Shoai M, Hardy J (2019) Polygenic risk score analysis of Alzheimer's disease in cases without APOE4 or APOE2 alleles. J Prev Alz Dis. 6:16-9. https://doi. org/10.14283/jpad.2018.46
21. Altmann A, Scelsi MA, Shoai M, de Silva E, Aksman LM, Cash DM et al (2020) A comprehensive analysis of methods for assessing polygenic burden on Alzheimer's disease pathology and risk beyond APOE. Brain Commun. 2:fcz047. https://doi.org/10.1093/ braincomms/fcz047

22. Skoog I, Kern S, Najar J, Guerreiro R, Bras J, Waern M et al (2021) A non-APOE polygenic risk score for Alzheimer's disease is associated with CSF neurofilament light in a representative sample of cognitively unimpaired 70-year-olds. J Gerontol A Biol Sci Med Sci. https://doi.org/10.1093/gerona/glab030

23. Morris MC, Tangney CC, Wang Y, Sacks FM, Bennett DA, Aggarwal NT (2015) MIND diet associated with reduced incidence of Alzheimer's disease. Alz Dementia 11:1007-1014. https://doi.org/10.1016/j.jalz.2014.11.009

24. Olsson E, Karlström B, Kilander L, Byberg L, Cederholm T, Sjögren P (2015) Dietary patterns and cognitive dysfunction in a 12-year follow-up study of 70 year old men. J Alz Dis 43:109119. https://doi.org/10.3233/jad-140867

25. Martínez-Lapiscina EH, Galbete C, Corella D, Toledo E, BuilCosiales P, Salas-Salvado J et al (2014) Genotype patterns at CLU, CR1, PICALM and APOE, cognition and Mediterranean diet: the PREDIMED-NAVARRA trial. Genes Nutr 9:393. https://doi.org/ 10.1007/s12263-014-0393-7

26. Hossain S, Beydoun MA, Kuczmarski MF, Tajuddin S, Evans MK, Zonderman AB (2019) The interplay of diet quality and Alzheimer's disease genetic risk score in relation to cognitive performance among Urban African Americans. Nutrients 11:2181. https://doi.org/10.3390/nu11092181

27. Barberger-Gateau P, Raffaitin C, Letenneur L, Berr C, Tzourio C, Dartigues JF et al (2007) Dietary patterns and risk of dementia: the three-city cohort study. Neurology 69:1921-1930. https://doi. org/10.1212/01.wnl.0000278116.37320.52

28. Barberger-Gateau P, Samieri C, Féart C, Plourde M (2011) Dietary omega 3 polyunsaturated fatty acids and Alzheimer's disease: interaction with apolipoprotein E genotype. Curr Alzheimer Res 8:479-491. https://doi.org/10.2174/156720511796391926

29. Samieri C, Lorrain S, Buaud B, Vaysse C, Berr C, Peuchant E et al (2013) Relationship between diet and plasma long-chain n-3 PUFAs in older people: impact of apolipoprotein E genotype. $\mathrm{J}$ Lipid Res 54:2559-2567. https://doi.org/10.1194/jlr.P036475

30. van de Rest O, Wang Y, Barnes LL, Tangney C, Bennett DA, Morris MC (2016) APOE $\varepsilon 4$ and the associations of seafood and long-chain omega-3 fatty acids with cognitive decline. Neurology 86:2063-2070. https://doi.org/10.1212/wnl.0000000000002719

31. Samieri C, Morris MC, Bennett DA, Berr C, Amouyel P, Dartigues JF et al (2018) Fish intake, genetic predisposition to Alzheimer disease, and decline in global cognition and memory in 5 cohorts of older persons. Am J Epidemiol 187:933-940. https:// doi.org/10.1093/aje/kwx330

32. Rinder L, Roupe S, Steen B, Svanborg A (1975) Seventy-year-old people in Gothenburg. A population study in an industrialized Swedish city. Acta Med Scand 198:397-407

33. Bengtsson C, Blohmé G, Hallberg L, Hällström T, Isaksson B, Korsan-Bengtsen K et al (1973) The study of women in Gothenburg 1968-1969—a population study. General design, purpose and sampling results. Acta Med Scand 193:311-318. https://doi. org/10.1111/j.0954-6820.1973.tb10583.x

34. Rydberg Sterner T, Ahlner F, Blennow K, Dahlin-Ivanoff S, Falk H, Havstam Johansson L et al (2019) The Gothenburg H70 Birth cohort study 2014-16: design, methods and study population. Eur J Epidemiol 34:191-209. https://doi.org/10.1007/ s10654-018-0459-8

35. Samuelsson J, Rothenberg E, Lissner L, Eiben G, Zettergren A, Skoog I (2019) Time trends in nutrient intake and dietary patterns among five birth cohorts of 70-year-olds examined 1971-2016: 
results from the Gothenburg $\mathrm{H} 70$ birth cohort studies Sweden. Nutr J 18:66. https://doi.org/10.1186/s12937-019-0493-8

36. Eiben G, Andersson CS, Rothenberg E, Sundh V, Steen B, Lissner L (2004) Secular trends in diet among elderly Swedes-cohort comparisons over three decades. Public Health Nutr 7:637-644. https://doi.org/10.1079/phn2003576

37. Rothenberg E, Bosaeus I, Lernfelt B, Landahl S, Steen B, Rothenberg E, Bosaeus I, Lernfelt B, Landahl S, Steen B (1998) Energy intake and expenditure: validation of a diet history by heart rate monitoring, activity diary and doubly labeled water. Eur J Clin Nutr. 52:832-838

38. Ax E, Warensjö Lemming E, Becker W, Andersson A, Lindroos AK, Cederholm T et al (2016) Dietary patterns in Swedish adults; results from a national dietary survey. Br J Nutr 115:95-104. https://doi.org/10.1017/s0007114515004110

39. Hoffmann K, Schulze MB, Schienkiewitz A, Nöthlings U, Boeing $\mathrm{H}$ (2004) Application of a new statistical method to derive dietary patterns in nutritional epidemiology. Am J Epidemiol 159:935-944. https://doi.org/10.1093/aje/kwh134

40. Monacelli F, Acquarone E, Giannotti C, Borghi R, Nencioni A (2017) Vitamin C, aging and Alzheimer's disease. Nutrients 9:670. https://doi.org/10.3390/nu9070670

41. Durga J, van Boxtel MP, Schouten EG, Kok FJ, Jolles J, Katan MB et al (2007) Effect of 3-year folic acid supplementation on cognitive function in older adults in the FACIT trial: a randomised, double blind, controlled trial. Lancet (London, England). 369:208-16. https://doi.org/10.1016/s0140-6736(07)60109-3

42. Robinson N, Grabowski P, Rehman I (2018) Alzheimer's disease pathogenesis: is there a role for folate? Mech Ageing Dev 174:8694. https://doi.org/10.1016/j.mad.2017.10.001

43. Dahl WJ, Stewart ML (2015) Position of the academy of nutrition and dietetics: health implications of dietary fiber. J Acad Nutr Diet 115:1861-1870. https://doi.org/10.1016/j.jand.2015.09.003

44. Gardener SL, Rainey-Smith SR, Martins RN (2016) Diet and inflammation in Alzheimer's disease and related chronic diseases: a review. J Alzheimers Dis 50:301-334. https://doi.org/10.3233/ jad-150765

45. Farina N, Llewellyn D, Isaac M, Tabet N (2017) Vitamin E for Alzheimer's dementia and mild cognitive impairment. Cochrane Database Syst Rev. 4:CD002854. https://doi.org/10.1002/14651 858.CD002854.pub5

46. Rehm J, Hasan OSM, Black SE, Shield KD, Schwarzinger M (2019) Alcohol use and dementia: a systematic scoping review. Alzheimers Res Ther 11:1. https://doi.org/10.1186/ s13195-018-0453-0

47. Shakya PR, Melaku YA, Page A, Gill TK (2020) Association between dietary patterns and adult depression symptoms based on principal component analysis, reduced-rank regression and partial least-squares. Clin Nutr 39:2811-2823. https://doi.org/10.1016/j. clnu.2019.12.011

48. Melaku YA, Gill TK, Taylor AW, Adams R, Shi Z (2018) A comparison of principal component analysis, partial least-squares and reduced-rank regressions in the identification of dietary patterns associated with bone mass in ageing Australians. Eur J Nutr 57:1969-1983. https://doi.org/10.1007/s00394-017-1478-z

49. Vermeulen E, Stronks K, Visser M, Brouwer IA, Snijder MB, Mocking RJT et al (2017) Dietary pattern derived by reduced rank regression and depressive symptoms in a multi-ethnic population: the HELIUS study. Eur J Clin Nutr 71:987-994. https://doi.org/ 10.1038/ejen.2017.61

50. Shin D, Lee KW, Kim MH, Kim HJ, An YS, Chung HK (2018) Identifying dietary patterns associated with mild cognitive impairment in older Korean adults using reduced rank regression. Int $\mathrm{J}$ Environ Res Public Health. 15:100. https://doi.org/10.3390/ijerp h15010100
51. Biesbroek S, van der Brosens Beulens Verschuren van der Schouw ADMCJWWMYT et al (2015) Identifying cardiovascular risk factor-related dietary patterns with reduced rank regression and random forest in the EPIC-NL cohort. Am J Clin Nutr 102:146-154. https://doi.org/10.3945/ajcn.114.092288

52. American Psychiatric Association (1987) Diagnostic and statistical manual of mental health disorders (DSM-III-R)

53. Blauwendraat C, Faghri F, Pihlstrom L, Geiger JT, Elbaz A, Lesage $S$ et al (2017) NeuroChip, an updated version of the NeuroX genotyping platform to rapidly screen for variants associated with neurological diseases. Neurobiol Aging. 57:247.e9-247. e13. https://doi.org/10.1016/j.neurobiolaging.2017.05.009

54. Blennow K, Ricksten A, Prince JA, Brookes AJ, Emahazion T, Wasslavik $C$ et al (2000) No association between the alpha2macroglobulin (A2M) deletion and Alzheimer's disease, and no change in A2M mRNA, protein, or protein expression. J Neural Transm (Vienna, Austria : 1996). 107:1065-79

55. Kunkle BW, Grenier-Boley B, Sims R, Bis JC, Damotte V, Naj AC et al (2019) Genetic meta-analysis of diagnosed Alzheimer's disease identifies new risk loci and implicates $\mathrm{A} \beta$, tau, immunity and lipid processing. Nat Genet 51:414-430. https://doi.org/10. 1038/s41588-019-0358-2

56. Rödjer L, Jonsdottir IH, Rosengren A, Björck L, Grimby G, Thelle DS et al (2012) Self-reported leisure time physical activity: a useful assessment tool in everyday health care. BMC Public Health 12:693. https://doi.org/10.1186/1471-2458-12-693

57. Huang TL, Zandi PP, Tucker KL, Fitzpatrick AL, Kuller LH, Fried LP et al (2005) Benefits of fatty fish on dementia risk are stronger for those without APOE epsilon4. Neurology 65:1409-1414. https://doi.org/10.1212/01.wnl.0000183148.34197.2e

58. Morris MC (2016) Nutrition and risk of dementia: overview and methodological issues. Ann N Y Acad Sci 1367:31-37. https:// doi.org/10.1111/nyas. 13047

59. van den Brink AC, Brouwer-Brolsma EM, Berendsen AAM, van de Rest O (2019) The Mediterranean, Dietary Approaches to Stop Hypertension (DASH), and Mediterranean-DASH Intervention for Neurodegenerative Delay (MIND) diets are associated with less cognitive decline and a lower risk of Alzheimer's disease-a review. Adv Nutr (Bethesda, Md). 10:1040-65. https://doi.org/10. 1093/advances/nmz054

60. Huang Y, Mahley RW (2014) Apolipoprotein E: structure and function in lipid metabolism, neurobiology, and Alzheimer's diseases. Neurobiol Dis. 72:3-12. https://doi.org/10.1016/j.nbd.2014. 08.025

61. McGrattan AM, McGuinness B, McKinley MC, Kee F, Passmore $\mathrm{P}$, Woodside JV et al (2019) Diet and inflammation in cognitive ageing and Alzheimer's disease. Curr Nutr Rep 8:53-65. https:// doi.org/10.1007/s13668-019-0271-4

62. Sato N, Morishita R (2015) The roles of lipid and glucose metabolism in modulation of beta-amyloid, tau, and neurodegeneration in the pathogenesis of Alzheimer disease. Front Aging Neurosci 7:199. https://doi.org/10.3389/fnagi.2015.00199

63. Arnold SE, Arvanitakis Z, Macauley-Rambach SL, Koenig AM, Wang HY, Ahima RS et al (2018) Brain insulin resistance in type 2 diabetes and Alzheimer disease: concepts and conundrums. Nat Rev Neurol 14:168-181. https://doi.org/10.1038/nrneurol.2017. 185

64. Gentreau M, Chuy V, Féart C, Samieri C, Ritchie K, Raymond $M$ et al (2020) Refined carbohydrate-rich diet is associated with long-term risk of dementia and Alzheimer's disease in apolipoprotein E $\varepsilon 4$ allele carriers. Alzheimers Dement 16:1043-1053. https://doi.org/10.1002/alz.12114

65. Kivipelto M, Rovio S, Ngandu T, Kåreholt I, Eskelinen M, Winblad B et al (2008) Apolipoprotein E epsilon4 magnifies lifestyle risks for dementia: a population-based study. J Cell Mol Med 12:2762-2771. https://doi.org/10.1111/j.1582-4934.2008.00296.x 
66. Hörnell A, Berg C, Forsum E, Larsson C, Sonestedt E, Åkesson A et al (2017) Perspective: an extension of the STROBE Statement for Observational Studies in Nutritional Epidemiology (STROBEnut): explanation and elaboration. Adv Nutr (Bethesda, Md). 8:652-78. https://doi.org/10.3945/an.117.015941

67. Skoog I, Börjesson-Hanson A, Kern S, Johansson L, Falk H, Sigström R et al (2017) Decreasing prevalence of dementia in 85-year olds examined 22 years apart: the influence of education and stroke. Sci Rep 7:6136. https://doi.org/10.1038/ s41598-017-05022-8

68. Najar J, Östling S, Gudmundsson P, Sundh V, Johansson L, Kern $S$ et al (2019) Cognitive and physical activity and dementia: a 44-year longitudinal population study of women. Neurology 92:e1322-e1330. https://doi.org/10.1212/wnl.0000000000007021 